\title{
Creative Expressions of Despair. Resilience and Psychic Potentiality
}

\author{
Juan Rodado', Máasosé Rodado² \\ ${ }^{1}$ Faculty of Medicine, University of Murcia, Murcia, Spain \\ ${ }^{2}$ Child and Adolescent Mental Health Unit, Los Arcos Hospital, San Javier (Murcia), Spain \\ Email: jvrodado9@hotmail.com, mrodado@hotmail.com
}

How to cite this paper: Rodado, J., \& Rodado, M. (2018). Creative Expressions of Despair. Resilience and Psychic Potentiality. Psychology, 9, 2573-2590. https://doi.org/10.4236/psych.2018.911147

Received: August 31, 2018

Accepted: October 28, 2018

Published: October 31, 2018

Copyright (c) 2018 by authors and Scientific Research Publishing Inc. This work is licensed under the Creative Commons Attribution International License (CC BY 4.0).

http://creativecommons.org/licenses/by/4.0/

\begin{abstract}
In the theory of Winnicott, a criterion of health is the psychic wealth. This is a concept not defined by the author, like so many others, that can be understood as the psychic ability to endure paradoxes. A capacity that starts from maternal care, which requires the maturity (evolutionary, non-chronological) of the baby. A skill that allows to maintain the subjective movement between the states of integration and non-integration of the subject. It also promotes the creativity of the baby in a possible space of play and exchange with the mother. Sometimes a traumatizing environment surrounds the individual and despite this, he manages to have creative expressions that show the psychic wealth. In these cases, where does the capacity called resilience come from? There are investigations that support the existence of primary unconscious motivations to solve problems and that the analytical link would allow them to develop them. Or considerations about a healthy capacity that would imply the existence of healthy unconscious potentials. In the present work we will address these situations of resilience. For this we will take the notion of restructuring bonding, where to the classical perspectives on the structuring value of the primary bond is added the restructuring potential of the secondary bonds. We will also take into account the conception of neuroplasticity. To explain these theoretical aspects, we will describe a clinical case of a 12-year-old adolescent with antisocial behaviors and a traumatic family history. In him, the existence of a healthy unconscious potentiality, repairing identifications and intense analytic work enabled the appearance of a creative act. A creative act that allowed him a libidinal and interrelational departure from his traumatic aspects.
\end{abstract}

\section{Keywords}

Resilience, Trauma Psychic, Creativity, Violence, Holding 


\section{Introduction}

In the theory of Winnicott, a criterion of health is the psychic wealth. This is a concept not defined by the author, like so many others, that can be understood as the psychic ability to endure paradoxes. A capacity that starts from maternal care, which requires the maturity (evolutionary, non-chronological) of the baby. A skill that allows to maintain the subjective movement between the states of integration and non-integration of the subject. It also promotes the creativity of the baby in a possible space of play and exchange with the mother. This exchange makes the baby feel alive, and enables his spontaneous gesture.

But what happens when maternal care has not been good? Sometimes a traumatizing environment surrounds the individual and despite this, he manages to have creative expressions that show the psychic wealth. In these cases, where does the capacity called resilience come from?

To answer this question we encourage you to join us in the following text.

\section{Determinism and Chance}

In current physics, the thermodynamics of irreversible and non-linear processes have discovered that the flows that pass through certain physic-chemical systems and move them away from equilibrium can foster phenomena of spontaneous self-organization. These phenomena evolve towards increasing complexity and diversity. Small fluctuations can, if they occur in appropriate circumstances, generate a new operating regime. The classic paradigm that identified growth of entropy with evolution to disorder has been replaced by the domain that combines the chance of fluctuations and the need for laws.

Near the equilibrium the laws of evolution are linear. When the system move away from the thermodynamic equilibrium, the processes are articulated in singular dispositions, sensitive to circumstances and to qualitative changes. In these cases, chance, a minimum fluctuation can decide the future. The system solutions are bifurcated. Systems, in this way, tend to new and unpredictable states that by their distance from equilibrium are called dissipative structures. Estructures that suppose a new state of the material. This new order is the order by fluctuations.

Luis Horstein (1994) tells us that in this new order, as psychoanalysts we are interested in two concepts; Adaptation and Self-organization. Self-organization is the transition to a new state of material. It is the order by fluctuations that supposes, at least punctually, the intervention of chance. These situations, moments called bifurcations express the limit of determinism. Self-organization thus represents the novel component and adaptation represents the routine and foreseeable component.

Modern science confers to chance a growing place in the explanation of complex phenomena. Chance plays an increasingly evident role in the logic of open, self-organizing systems. If a system, under the effect of random perturbations, reacts with an increase in complexity instead of being destroyed or disorganized, 
it is defined as self-organizing.

An organization that can not be disturbed by new noises is headed for a deadly closure according to the principle of entropy. From the idea of an open system, two consequences arise: 1) The laws of the organization of the living are not of equilibrium, but of imbalance rebalanced or compensated, of stabilized dynamism. 2) The intelligibility of the system must be found in its relationship with the environment. If the system is "open" its existence is inseparable from interrelations with the environment, through which the system draws from the outside matter, energy and information (Morin, 1982).

Thus in an open system an "intrusion" from the environment does not necessarily imply disorganization, or another level of equilibrium, as in a closed system.

Can this logic of open systems be extended to psychic functioning? We will say that this is possible. The trauma can lead to a more complex reorganization.

\section{Play as a Random Element}

Let's look at the scene of a two-year-old child. At that age the child will want to play. But he does not have a fixed plan about what he wants to play. The direction of the game will depend on what he finds. The game depends on chance encounters. Ricardo Rodulfo (2012: p. 145), Argentine psychoanalyst says that it is not licit to postulate, in these avatars of the game, that each object found, created, symbolizes the inevitable papa and mama.

Play always implies something random. To talk about playing and playing there must be at least more than one possibility. Rofulfo (2012: p. 148) points out that what is fixed, what is necessary, what can only be so, the law to be fulfilled, the only possibility, the cause par excellence, all that bouquet of endearing motives of our metaphysics, antagonizes the space itself where the play can and aspires to be. Playing is on the side of the event, of what will happen without knowing that, something that was not foreseen.

Play, in the words of Cristina Marrone (2005), is an exercise of freedom over the real. Besides the game, it is in itself, "Stellung". This is a German expression that indicates a position and even a disposition or attitude. Open attitude, which requires that something of the other comes into play. The game is set up when something of the care-illusion of the other, of love as the edge of the familiar, alienates but at the same time protects and allows the opening towards the future.

This leads us to wonder about the imagination. Imagination is considered as a hinge of the playful. It transforms passion into pleasure, "too much" or "excess" into that other regulated satisfaction. The imagination operates by establishing fiction, reality effect, a reality that is not all reality. Therefore the imagination is as a condition of the playful. The product of the faculty of imagination modifies the subject. It would be a return on itself but in a fictional way that is what the imagination allows. 
In Kant (1991: p. 216) the connection between the notion of genius and that of imagination concerns the aesthetic field. The conjunction of imagination and genius leads to the idea of play. That is, it is not the one who knows but the one who, with his doing produces and can come to know something. The knowledge is produced as a consequence of said doing. Thus the conjunction of imagination and genius leads to the idea of game.

Rodulfo (2012: p. 153) proposes to play as an event that founds and coincides with the subjective activity itself. It is not a reaction but an original practice, not connected with anguish but with joy, with the violence of joy, intrinsically linked to the production of differences sought through repetition. And in this he contrasts it to the idea of the Freudian principle of inertia that proposes that the absence of stimulation is the human capital desire. Rodulfo says no, and raises the search for difference as postulate.

Playing is therefore a proposal for the production of stimuli and not a response. The toy is a product of the game. All the acquisitions a child makes are made through playing as a general praxis.

\section{Neuroplasticity, Neogenesis and Restructuration Bonds}

There are researches that support the existence of primary unconscious motivations to solve problems and that the analytic link would allow them to be developed (Weiss, 1998). Or considerations about "healthy virtuality" (Badaracco, 2005) that would still exist in the most serious patients, and that would imply the existence of healthy unconscious potentials.

The fact that a baby plays exceeds its biological nature. One can not justify playing by appealing to a "basic" or "biological" need traditionally considered. The desire to play, the need to play, the spontaneous emergence of playing is not taught to the baby by anyone. It is an unconditioned, unpredictable, unredetectable emergency. Certainly the adult plays with that baby, but did not give "that" to the baby. That which makes anything, a spoon, a button, a sound..., becomes an object of play. It is to this unconditioned, original emergency that following Winnicott (1990) we will call spontaneity.

The baby, far from passively submitting to the law of the medium, introduces a certain order in the medium, a series of differences in the face of which he reacts. In addition, in these first years of life the brain is in a maturational process in which new neural connections are continuously established and the growing growth of its structures takes place.

Neuroplasticity is the ability of the brain to increase or decrease the number of neuronal branches and synapses, from the stimulus on the cerebral cortex. It allows a greater capacity of adaptation or readaptation to the external an internal changes. Neuroplasticity also ensures that connections with other neurons increase and that these with experience are stable. It also enables learning and sensory and cognitive stimulation.

We have innate spontaneity and neuroplasticity. There are many synapses or 
neural connections that are little or not at all functional. This means that these connections fail to be effective for a function. They are "half-asleep" and not fully activated until they are integrated into a brain network that responds to a behavior or function. It is therefore the response of the medium that would enable this. We think that there is a potentiality waiting for a suitable means.

But how can we explain that some patients, victims of traumatic situations, manage to transform the adverse into a stimulus to develop a successful capacity and others succumb to such experiences? We will introduce here the term of resilience that will help us in the understanding of clinical situations in which the subject faced adverse experiences.

The term comes from physics and was used to describe the ability of some materials to recover their original form after being subjected to a transforming pressure. However, the concept of resilience is relevant in the field of health.

Authors such as Rutter (1987), Fonagy, Steele, Steele, Higgitt and Targe (1994) define it as the process or ability to develop a successful adaptation in circumstances associated with psychological dysfunction and low competence. For Grotberg (2001), resilience is the human capacity to face and overcome and be strengthened or transformed by experiences of adversity. Kreisler (1996) understands it as the capacity of a subject to overcome circumstances of special difficulty, thanks to his mental qualities of behavior and adaptation. Vannistendael (2000) defines it as the ability to succeed in an acceptable manner for society, despite a stress or adversity that normally implies a serious risk of negative results.

All the definitions allude, to our understanding, to a capacity of transformation that implies a psychic process. From our point of view, it is important to take into account not only a dynamic perspective (depending on risks and time) but also a community perspective. That is, to think about the role that family, social and/or community bonds can have in the development of resilient behaviors and attitudes. It is a vision hopeful that includes the promotion of resilience. And in the treatment will take into account the intrinsic features (individual characteristics), cultural significance and also the link with the other.

Zukerfeld R. and Zonis Zukerfeld R. (2005) assumes that resilient development in the face of adversity consists of a subjective metamorphosis, the product of the activation of a potential that serves to create new psychic conditions. These conditions transform the traumatic effect with the indispensable existence of new intersubjective bonds.

Cyrulnik $(2003,2005)$ international leader in the development of the resilience paradigm, emphasizes that the child's resilience is built on the relationship with the other, through the "knitting work" that weaves the bond. Intrauterine communication, affective security from the first months of life, and later the interpretation given by the child to events are other elements that favor resilient development. Therefore, the author gives a fundamental value to the attachment to 
the point that he developed the notion of a resilience guardian. This concept refers to someone, a person, a place, an event, a work of art that causes a rebirth of psychological development after trauma. A meaningful encounter may be enough. In the clinical case that we will be presented below, these attachment figures appear and they will take care of the child and even make possible the treatment.

Cyrulnik (2001: p. 92) writes that all pain is bearable if we turn it into a story. He also says that: "Those who say "early disturbances, durable effects" are told that early disturbances cause early effects, which can last if the family and social environment turns them into permanent stories.

Returning to the idea of transformation that we proposed, resilience as Rozenfeld (2005) explains, it is convenient to think of it as a new destiny of trauma, a new subjective position and therefore it is not synonymous with the resolution of trauma. It is not a mere resistance or absence of symptoms. Nor can it be reduced to the psychoanalytic notions of sublimation, repair or denial, although these mechanisms can be described in resilient subjects.

As conclusions and taking into account the notions of determinism, play and neogenesis, we will highlight three ideas about resilience.

First idea: The resilience, in our opinion, is connected with this notion of open system, influenced from the outside. The stimuli-aggressions put at risk of disorganization to the system and at the same time preserve its vitality.

Second idea: The notion of resilience is connected to this ability to play, a potential capacity that coincides from our point of view, with the so-called spontaneous gesture of Winnicott.

Third idea: Resilience is connected with the subjectivizing capacity of the bonds. This alludes to the existence of a plastic possibility to change one's own thinking based on an empathic perception of the other. It involves both convincing and being convinced. For this it is essential to first understand/translate the language/thought of the other.

These Ideas will support the clinical work discussed in this article and that we expose below

\section{Jaime}

We will finish this work with the presentation of a clinical case. The questions, the unexpected findings arising from the clinical work are those that force us to reflect and review the theory.

It is about an antisocial teenager that we will call Jaime. We took from Winnicott (1991) the meaning of the antisocial act when describing the deprivation suffered by patients who committed these acts. This author considers that the antisocial act implies hope and that the deprived child manifests this tendency in his hopeful periods. The child seeks through destructiveness the degree of environmental stability capable of resisting the tension caused by his impulsive behavior, looking for someone to trust. Through the act, the child pretends to take a regressive leap to the period prior to the time of deprivation and redis- 
cover both the good object and the good environment that controlled him and that initially enabled him to experience the impulses (including the destructive).

We will explain these more carefully. For Winnicott the concern (word that he uses in a positive sense to refer to the phenomenon of guilt) is described in terms of the mother-baby relationship. Worry appears when the child perceives the mother as a whole person. It also implies a certain degree of integration of the individual self. This integration allows the conservation of the Imago of the good object together with the idea of destruction. Therefore the feeling of guilt (concern) is linked to the concept of ambivalence. In other words, with the ability of the baby to incorporate the two experiences (erotic and aggressive) and to do so with respect to the same object.

The capacity for concern will depend on the good enough care provided to the baby and the child. Winnicot's idea of the existence of two mothers "mother-object" and "mother environment" for the immature baby seems to us a clear representation of the two aspects of parenting. These two aspects are that of the mother seen as a partial object that must meet the urgent needs of the baby and the mother environment that would be the person who provides active care and protects it from the unpredictable. The mother environment receives what can be called affection and sensual coexistence, while the object mother becomes the target of the excited experience. It is within the process of reunion of these two mothers, a complex experience in which the worry appears in the baby. Instinctive motions lead first to the uninteresting use of objects and to a later feeling of guilt that is borne because the mother-environment contributes to the repair. But if this opportunity to repair does not arise, because the mother-environment fails, guilt appears in a latent or potential state. Even the baby can lose that ability to worry about appearing more primitive anxieties and defenses such as splitting and disintegration. It can also happen that early experiences do not allow integration, in the child there is no unity and therefore there is no possibility of feeling responsible.

With the Winnicottian theory and considering the hope that the author observes in the antisocial act, I began Jaime's treatment.

The first time I heard about Jaime was when Cesar, Jaime's uncle, came to my private office. He had the intention to initiate an analytic treatment with me, but finally he refused it. Cesar had a turbulent past with antisocial incidents, toxic consumption, and a truculent family history.

In the interview with César, he referred to his nephew Jaime, aged 12, as someone violent with the family. They did not know what to do with Jaime. They could not contain him. For these reasons the family made a consultation at the mental health center. Jaime was treated by a psychiatrist who prescribed him haloperidol. After a very short period the family abandoned the treatment because there was little improvement and visits were rare. Although Jaime remembered every day to take the treatment. This seemed positive in the sense of 
assuming the uncontrolled behavior. As well as what the drug could represent for him.

With this story, the figure of Jaime, who practiced karate, was gigantic before me. Waiting for him produced a mixture of excitement and fear that dissipated when he appeared. In the first interview he was accompanied by his maternal aunt, with whom he lived.

Jaime's physical appearance and attitude were closer to childhood than puberty. He was short and hid shyly behind a smile. He remained silent when entering the office. In the presence of Jaime, his aunt told the reason for consultation. She told me that Jaime does not behave well, they punish him and he seems not to learn from the experience, because he always repeats the same misdeeds. He recently drove a neighbor's motorcycle without his permission. Jaime is very restless and rebellious since he was little. He also presents tics and makes facial grimaces.

I was alone with Jaime. I asked him what he thought about what his aunt said. He remained silent, smiled and between the teeth let out a yes, "well yes, it is true what my aunt said". Spontaneously he chose the couch to sit down. He began to hum in a low voice. He told me "tonight I am punished, Eduardo has told me", "he is my aunt's companion". To the question of why the punishment answered "I have broken a thing of the television". I have to stay in my room locked with the light turned off, although punishment is not always the same. Other times they lock me in the water for a few hours."

In a second interview I met aunt and Jaime's grandmother. The maternal grandparents took care of Jaime until about a year ago that he moved to live with his aunt. The advanced age of the grandparents, the health problems of them and an accident that the grandfather had made difficult the continuity of Jaime's care. At the aunt's home, Jaime lives with his aunt, his cousin Guillermo (aunt's son) and Eduardo (aunt's partner).

However, sometimes Jaime spends the weekend at the house of his grandparents. Grandma seemed a very nervous woman to me. The whole interview she kept verborrheic and grandiloquent.

Both (the aunt and the grandmother) said that Jaime was a desired child. The aunt said: "The parents could put a remedy" "I told my sister that she could have an abortion but they decided to have the son". The grandmother added: "He has the same temperament as the father, If he says something, it has to be done immediately. I have panic Jaime. He is going to kill us (in the sense of exhaustion) one of these days".

\section{Jaime's personal story}

When Jaime was born, he lived with his mother at the home of the maternal grandparents. The father ignored the father's functions. The grandmother said: "Grandma said; "Jaime's father came for my daughter and took her away, I was afraid for her. She was a good girl and obedient but he was evil and convinced her. When my daughter came back she was devasted by the drugs she was tak- 
ing. My daughter always told us that she was going to change but nothing changed. "My daughter had the bad luck to come across that element (that's what she meant when talking about Jaime's father)".

Jaime was a premature child who needed to be in the incubator. His mother was HIV positive and for that reason he was fed with a bottle. He was born with positive antibodies to HIV. After six months these were negative. The grandmother said that she assumed the grandson's upbringing. They both (the aunt and grandmother) remembered Jaime as a healthy child, robust, and good to eat "from very small he eats everything". There was no evidence of a delay in psychomotor development.

At the age of two years he started the nursery. According to aunt, he adapted well at the beginning but at that age some aggressive behaviors appear. "Since he was a child he was violent and aggressive, especially with his cousin Guillermo, whom he envies" says the grandmother. Guillermo is constantly appointed by both (grandmother and aunt) and always with flattering qualifications ("if Jaime were like Guille, but not).

\section{Jaime's parents}

Jaime's mother died four years ago. A year before, the father died, with whom Jaime barely established a bond. The relationship of his parents was conflicting and difficult. Also the relationship of his father and his maternal grandparents. On some occasions the father, in the presence of Jaime, presented verbal violence to the mother.

Jaime did not talk about his father. And when his mother died, he did not want to talk about her. His aunt said that when someone asked him, Jaime did not answer and left.

\section{The school}

Jaime was not a good student. Behavioral problems at school began after his mother died. Jaime was aggressive with his schoolmates and did not respect the rules. Both teachers and parents complained about him. He was expelled from the school canteen and could be expelled from school if he continues with this behavior.

His aunt said: "He does not study. He is advancing course but does not have the level that should. He does not like reading. I do not know what subject he likes, if he likes any". "He was going to an academy but we have removed him because the professors said that Jaime did not want to do his homework".

Currently a student goes home to help him with homework. Jaime appreciates her very much and misses her if she does not come. This caught my attention as well as and encouraged me. I thought he could bond with someone.

\section{Social and Family Life}

Aunt describes him as quiet and shy when he is with people he does not know well. And terrible when he has confidence with people. She says "Jaime has few friends but he does not want to play with them. At home he has many manias. 
He has to touch the ceiling and the walls repeatedly. Always he climbs the stairs jumping and touching the ceiling. If I kiss him, he wipes his face. He does not like to be kissed. Jaime tells his grandmother that I do not want him and everything is because in my house he has to obey".

The grandmother comments on him: "I do not know how to treat him when he comes to my house. He insults me by calling me a motherfucker and old lady. He gets angry if the food is not ready when he comes in. He respects his grandfather more than me. Before the accident the grandfather went out for a walk with Jaime." I had the impression that the grandfather was an important figure for Jaime and had exercised the functions of a father.

I asked both of them if there was anything that Jaime liked. The aunt answered that Jaime plays football and he likes it a lot. Jaime trained in a club that was close to the aunt's house. For a few months now, he has gone to another club in the neighborhood where the paternal grandparents live. They decided to change but do not commit to carrying him every week.

\section{Sessions with Jaime}

In the first sessions I was tense, unwilling to play. The first day Jaime and I sat on the divan. I asked him why he thought he was coming here and that they explained him. We also talk about his friends, hobbies, studies. Although Jaime was shy and not very talkative. The second day, we both sat next to the desk in my office. I showed him paper, pencils and markers inviting him to draw. He was lazy as tired. We begin the game of the doodle. If I started with easy lines, he continued with interspersed lines that made it difficult to obtain a drawing.

Jaime, in the game, made it complicated for me. He smiled when he noticed my difficulty. In the third drawing he said "what's in my kitchen". From there we went drawing his house and the people who lived with him. The time passed slowly. I look forward to the end of the session. A stupor was taking over our relationship. Both his writing and his drawings looked like those of a younger age. He picked up the pencil strongly as if in tension. In each drawing he finished the tip of the pencil.

In the third interview I asked him to use the colors and draw his grandparents and him. When drawing grandparents, he continued with some stroke. I asked him to continue. Then Jaime blushed saying that what he drew was nothing. I insisted him to continue drawing and he drew another figure. But but he said he did not know who he was. We kept the drawings in a drawer, to think together who that figure was. Some of his drawings refer to individuals who are violent or intransigent. Below we show some of these drawings. (See Figures 1-3).

This day I asked him if he dreamed. He answered that sometimes. He told a very short dream: "There was me and my friend Carlos. We were riding motorbikes on the road. It was a very long road, in which there was nobody. We were going with two motorcycle bikes. "After listening to the dream, I felt another moment of tension. I did not know how to continue. Jaime began to 


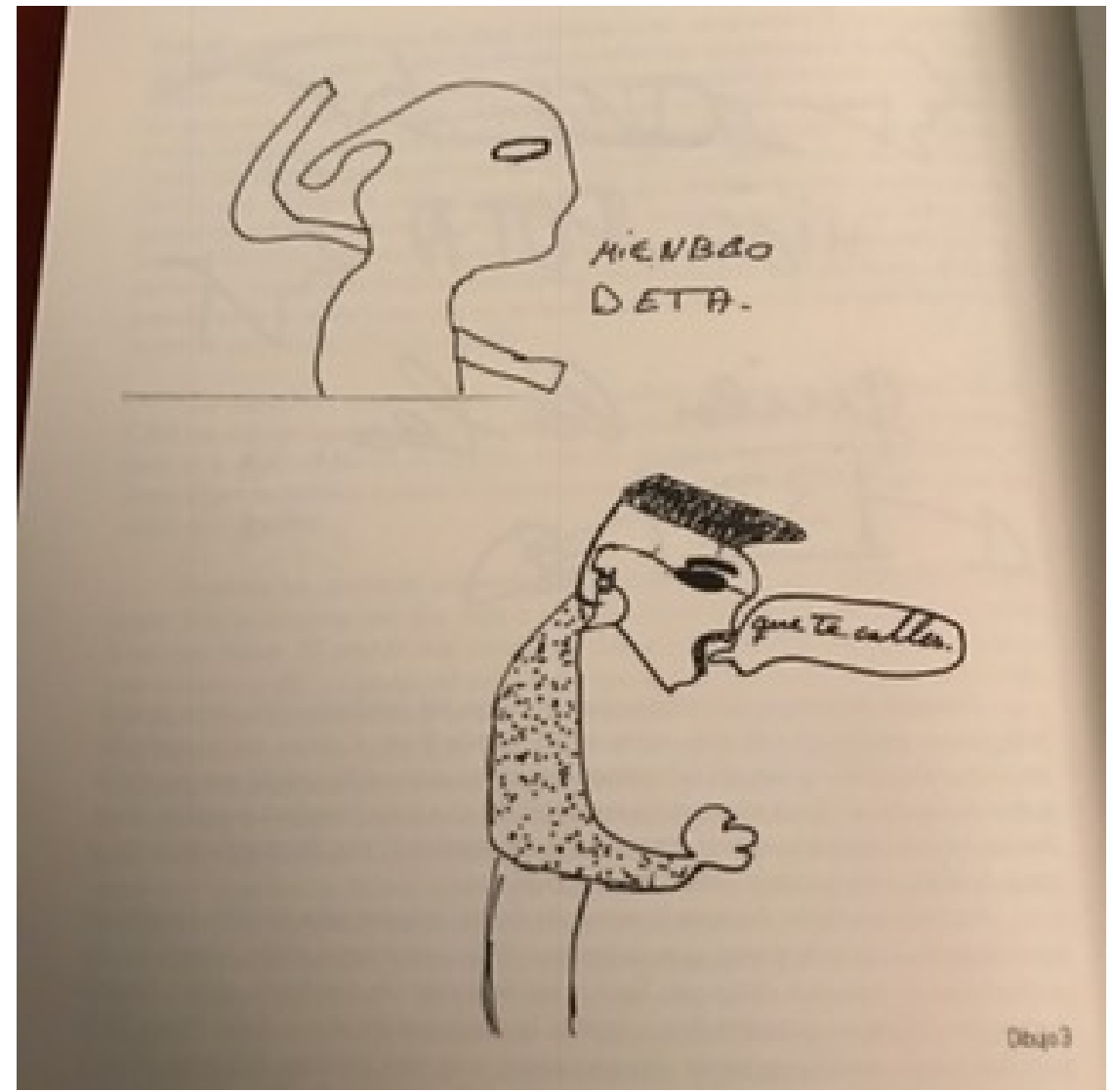

Figure 1. Two figures: “A Member of ETA (an armed band in Spain)". Below another figure that says "Shut up". From our point of view Jaime represented the destructiveness towards others through those violnet figures.

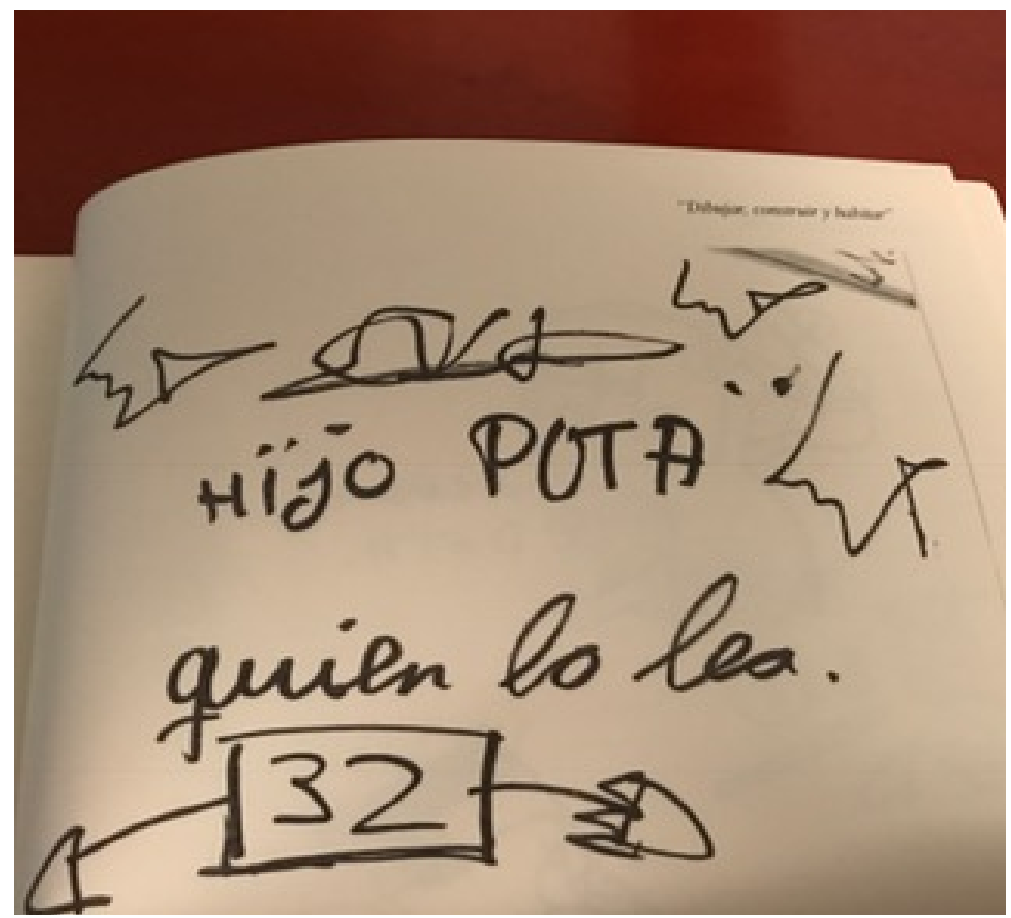

Figure 2. "Motherfucker who reads it". 


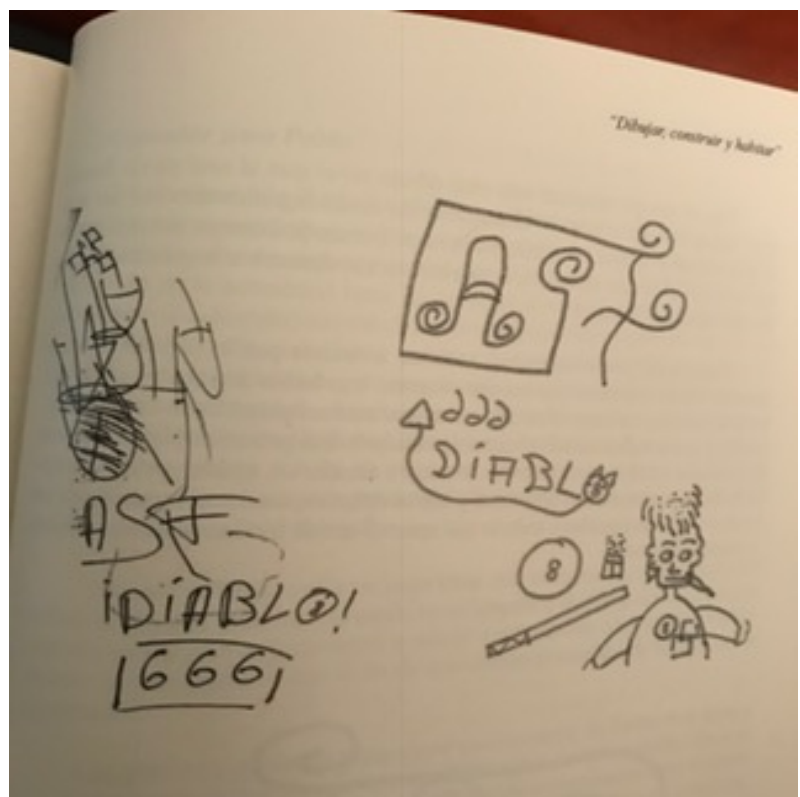

Figure 3. In the drawing we see the initials "AGF". These letters are the initials of his first name and surname. Bellow the initials and also on the right side, the number " 666 ". For him this number was the devil number. On the lower right side on the page he represented "the ball number 8 or black ball of the billiard". Also a young man figure. He said "whoever puts the ball in the hole loses. From our point of view these figures represented the destructiveness directed toward himself.

hum the song of a series that he liked a lot. The companions series that he could not see that night because he was punished. He told me the reason for the punishment.

\section{The Game with Jaime; the Scribble and the Physical Games}

During the first year we alternated the game of scribble, with more physical games in which Jaime was freer. The sessions with him were, in their majority, in a climate of constant tension. Anything could happen; that he would hurt himself, that some object would break or that I would be harmed by some of his actions. Sometimes he drew making myself fall into traps.

Sometimes I was surprised to find him laughing happily while hitting the ball with my hand so that I could return it to him. These moments encouraged me to continue the treatment to face those other distressing moments. The latter were frequent, long-lasting and very difficult for Jaime and me.

\section{From Physical Space to Sound Space}

After a little more than a year, part of his identity appeared in his scribbles. Although Jaime was still defensive, he began to show me his signature, as it was composed.

He also told me about his grandparents. What caught my attention was that the situational tension (tension of "physical space") existing during the sessions was transformed into a tension related to sound. As an example I will say that 
Jaime opened a window of my office and showed part of his body as if he wanted to jump. I tried to protect him and he allowed me to hold him.

Jaime suddenly, up and down the volume of a CD that brought to the office. or hit the table of my office. These actions startled me. Other times we played with an old stethoscope that I had. He invented the following game; one tapped the stethoscope's membrane while the other listened to the amplified noise. Sometimes he would mutter a song and if I asked he would scream.

I confess the moments of exhaustion in the sessions and my feelings of impotence. On the one hand instinctively, to protect him and me, Jaime asked me to end these maneuvers loaded, sometimes, with a certain sadism. But on the other hand I thought it was the only way that Jaime had to communicate with me, or rather to communicate a situation that could not thought for him (in the words of Bollas, that which is part of the known not thought). For Jaime who was I in those moments? What was happening to me?. I was subjected to extreme tension, which results from always being aware that the object does not disappear, do not leave. From my point of view, Jaime was able to experience this way his parents, who with the repeated consumption of toxics were continually exposed to death. Jaime made me feel what he must have felt with his parents. I was also subjected to continuous and changing sound sensations. Sensations derived from the encounter with someone whose actions were changing and not predictable. Jaime, in my construction, it is possible that he had been subjected to the violence of caregivers. I asked myself: What was the response of his mother or father, when Jaime was a baby, in times of stress and anguish?. How did these parents codify the needs of the baby?. that they could not take care of themselves, the needs of the baby? Keep in mind that these parents could not take care of themselves and the existence of a baby could have added stress.

\section{A Creative Act}

An act of Jaime represented for me one of the possible exits in the face of so much madness and helplessness. He brought to the session a small radio cassette on which he had recorded a tape. On the tape, manipulating the controls of the device, he made variations with the background sound. For me this meant a sign of hope. He told me he wanted to be a DJ. From that moment on, the music changed. On the original he wanted and could make variations. He asked his uncle, a musician at another time, an old mixing table and he has become fond of the music performed by certain DJs. He knew the names of many Djs and the different types of music. Jaime started making some recordings.

Although Jaime's behavior, at times, was similar to that presented at the beginning of the treatment, this creative act with the music was an important gesture. I thought about the importance of such a gesture when pessimism invaded me. To the existing complicity between the two, an instrument was added that allowed us to "mix" our music, which I had installed and what he brought to the sessions. In short, an analytical treatment is this, the common unconscious space 
that Nasio (2013: p. 167) would say, something that is partly of the analysand and partly of the analyst. Jaime from time to time drew a mix table and we played to mix together; other times he showed me what he had done at home, his last recording. The echoes of a poor childhood, of an atrocious environment that left the imprint of a tantalic and persecutory superego that constantly propels him towards antisocial acts, to transgress the law, still resounded. A confession from the aunt gives an account of the traumatic reality in which Jaime lived. The aunt told me that Jaime's mother, when he was little, took him with her to buy drugs. Jaime remembered that scene and could talk about it.

Once and for reasons of my work we had to suspend the treatment for a week. When he saw each other again Jaime brought me the little radio cassette, but there was nothing on the tape. He got nervous and pissed off when he rewinds to find something. Furious, he picked up one of my cards that is on the table and tried to insert it through the slot of the cassette. I was touched by his attempt to reestablish a communication and to observe the necessity of it for him.

The treatment lasted three years, time between the two of us, we were able to build a trustworthy therapeutic space, where, starting from the creative act of the mixing table and the DJ, Jaime began to show hope for the future, for a future in which I imagined him dedicated to music. He recorded and mixed cassettes and put his name on it. He was also able to enter a special secondary school study program for children at school risk, where he began to study hospitality and work in that sector.

The psychotherapeutic work lasted 5 years. A year ago I met him in the street in a fortuitous way, after two years without knowing about him. Jaime was studying mechanics and he got the driver's license. His next plans were to go to work after finishing the course and renting an apartment. He kept mixing music and had recorded a couple of CDs with friends for a local club where he sometimes let him play music. The evocation of the treatment made me think about the sound universe of Jaime and the sonorous experiences that we find in the first months of our life. In the case of Jaime, an adverse sonic universe reissued in the transference during the treatment.

Stern (1991: p.145) asks himsef if someone can be intoned in the anger that is directed against him. A subject can experience the level of intensity and quality of feeling that has arisen in the other and that could arise in oneself. But this does not mean that the person is sharing the anger of the other because the subject can be involved in his own feeling possibly of helplessness, fear, guilt, etc. The initial knowledge of the infant is mainly incompartible, amodal, specific in each case, intoned with nonverbal behaviors in which no communication channel has a privileged status. Language changes everything. The language opens a space between the personal experience lived and the one represented. But also with language the infant can share with others his personal experience of the world that includes "being with" another in intimacy, isolation, loneliness, fear, reverent fear and love. How this language is presented to the baby, used with 
him (of its frequency, parsimony or not, of its intonation...) will depend on this ability to share and "be with" others and with itself.

And what can we say about Jaime's own anger? Is it good or is it bad? Who can say if in essence fire is destructive or constructive?

To explain it Winnicott (1975: p. 26) says that we include in that first destructive impulse avidity, salivation, expiration, combustion and certain sensitive experiences, such as extreme sensory sensitivity in the first minutes immediately after birth, as well as certain characteristics of smell, phenomena that are intolerably real for the baby, or slightly less, even in sufficiently good conditions of support and manipulation.

Intolerably real. The vital sensations are intolerably real. Life is intolerably real, or slightly less. Experience to the limit that requires another that supports the thrust of life that in its almost overflows we found.

In that vitally important stage, I live it "destructive" (fire-air or otherwise), it's simply a symptom of being alive, and it has nothing to do with anger because of the frustrations inherent in running into the reality principle.

The motion is destructive. At that moment the survival of the object (object or subject?) Leads to the use of the object and to the differentiation of fantasy and the effective location of the object outside the area of the projections.

Therefore, this very early destructive impulse fulfills a positive vital function (when it operates, through-through the survival of the object), namely, the objectification of the object. "

\section{Conclusions}

In the clinical case, the story of a boy who has suffered emotional deprivation at a young age is described. He was exposed, to the death of his biological parents and to situations of intrafamily violence. However, the destructiveness directed towards himself represented in his drawings ("the 666 of the devil" or "the one that always leaks the black ball and loses") and towards the others, (as it appears in the drawings when representing an ETA member or the man who shouts "that you stop"), and the aggressiveness in his daily acts, also reflects a a boy who, despite his traumatic experiences, is open to the real world. Jaime was a child who did not make an emotional withdrawal and could show interest in his surroundings. A child who had mental representations of both his family and the non-family world. In addition, the psyche of Jaime could be considered and open system if we take into account the concepts of determinism and chance that appear in the introduction of this paper. That is a system that can be influenced from the outsider. In this system also the aggressive stimuli can contribuye to its disorganization but at the same time this type of stimuli preserves the vitality of the system.

In Jaime's treatment we also observe the existence of creative gestures and an ability to play, a potential capacity that coincides with what Winnicott calls a spontaneous gesture. These creative gestures that we mentioned were observed in some of his drawings (for example, the elements that we show in Figure 4) 


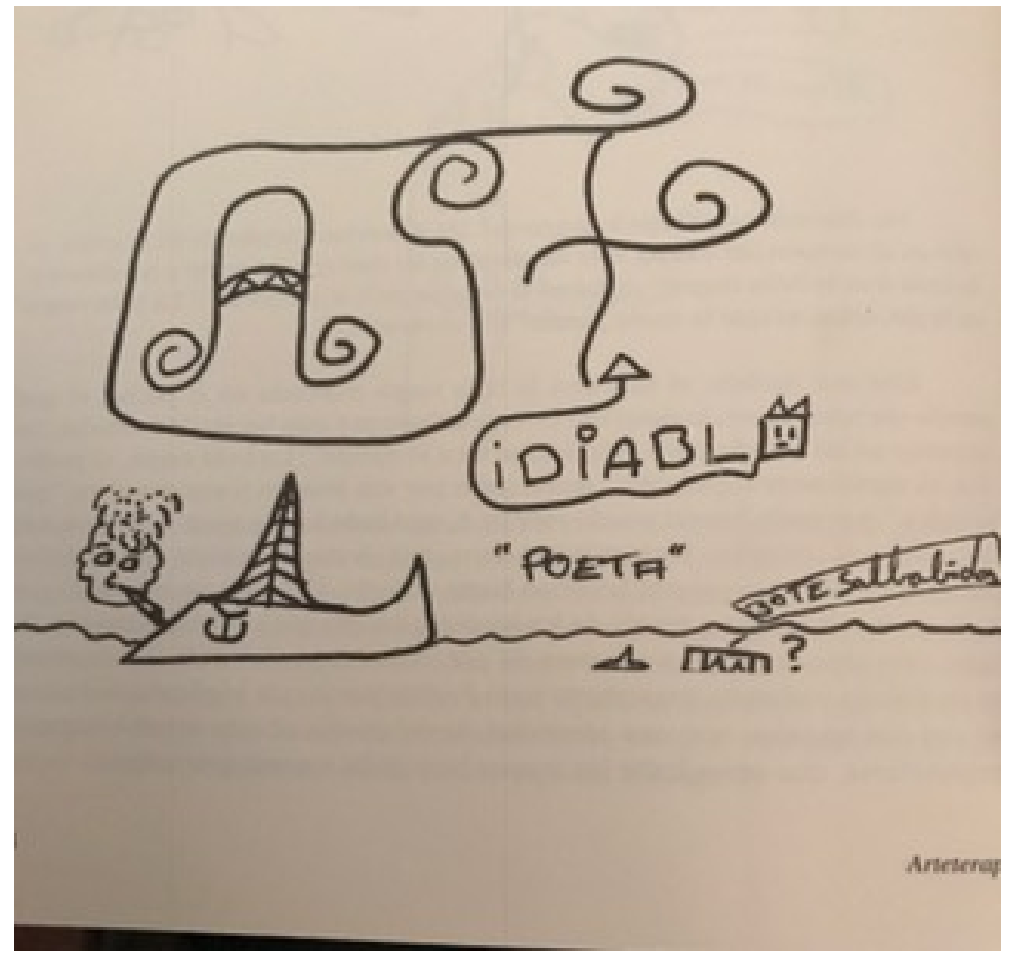

Figure 4. In this drawing we see that in his signature (the initials) begins to appear some modification and next to the word devil (seen in other drawings), new elements such as a lifeboat and the word poet. We consider the appearance of these elements as creative gestures.

and in the creation of the music that emerged in the sessions.

The clinical case also shows the plasticity that in a bond is expressed as improvisational capacity and presents someone who has a subjectivity capacity.

In order to better study the topic, we think that this paper has some deficiencies. One of them is subjectivity. It is difficult to transfer to a narrative everything that happens in each one of the sessions, in the encounter between two unconscious ones. Botella C. and Botella S. (2003) describe that in both the analyst and the analysand there is a psychic state exclusive to the analytic session that they call session status. This is a psychic state of a unique and singular nature and with an operation in which qualities of both the primary (unconscious) and secondary (conscious) processes appear. Unconscious and conscious elements appear in each session. And the first ones (unconscious), when we describe them although they acquire a greater logic, at the same time they are deformed by the secondary process. On the other hand, the exposition of a single case, as we do in this article, is a limitation to generalize the conclusions.

However, despite the limitations, we consider that the case illustrates the importance of the links as transforming capacity. It also highlights the need to look for resilient elements when we face people with traumatic experiences and in those cases where the trauma of the patients invades us and limits our ability to 
think like therapists.

\section{Conflicts of Interest}

The authors declare no conflicts of interest regarding the publication of this paper.

\section{References}

Badaracco, G. (2005) El psicoanálisis multifamiliar: cómo curar desde la "virtualidad sana". [Multifamily Psychoanalysis: How to Cure from the "Healthy Virtuality"]. Revista de Psicoanálisis, Buenos Aires, 62, 919-936.

Botella, C., \& Botella, S. (2003) La figurabilidad psiquica [The Psychic Figurability]. Amorrortu Ed., Buenos Aires.

Cyrulnik, B. (2001) La maravilla del dolor. El sentido de la resiliencia [The Wonder of Pain. The Sense of Resilience]. Barcelona: Editoril Granica.

Cyrulnik, B. (2003) Los patitos feos. La Resiliencia: Una infancia infeliz no determina la vida [Ugly Ducklings, Resilience an Unhappy Childhood Does Not Determine Life]. Barcelona: Gedisa.

Cyrulnik, B. (2005) Bajo el signo del vinculo [Under the Sign of the Link]. Barcelona: Gedisa.

Fonagy, P., Steele, M., Steele, H., Higgitt, A., \& Target, M. (1994). The Theory and Practice of Resilience. Journal of Child Psychology and Psychiatry, 35, 231-257.

Grotberg, E. H. (2001). Nuevas tendencias en resiliencia. En A. Melillo y E. N. Suarez Ojeda (comp.), Resiliencia: Descubriendo las propias fortalezas (pp. 19-30). Buenos Aires: Paidos.

Horstein, L. (1994) Determinismo, temporalidad y devenir [Determinism, Temporality and Becoming]. En J. Bagnato, S. Bleichmar, R. Bernardi, A. Ford, L. Hornstein et al. Temporalidad, determinación, azar. Lo reversible y lo irreversible [Temporality, Determination, Chance. The Reversible and the Unreversible]. Buenos Aires: Paidos Psicologia Porfunda.

Kant, I. (1991) Critica de la facultad de juzgar [Criticism of the Ability of Judging]. Monte Avila editores, Caracas.

Kreisler, L. (1996). La résilience mise en spirale. Spirale, 1, 162-165.

Marrone C. (2005) El juego, una deuda con el psicoanálisis [The Game, a Debt of Psychoanalysis]. Buenos Aires: Editorial Lazos.

Morin E. (1982) Ciencia con conciencia [Science with Conscience]. Paris: Editorial Fayard.

Nasio, J. D. (2013) Como trabaja un psicoanalista [How a Psychoanalyst Works]. Buenos Aires: Paidos.

Rodulfo, R. (2012) Padres e hijos. En tiempos de la retirada de las oposiciones [Fathers and Sons. In Times of the Withdrawal of Oppositions]. Buenos Aires: Paidos.

Rozenfeld, A. (2005). Presentación en grupos de discusión. 44 Congreso Internacional de Psicoanálisis, IPA, New Orleans.

Rutter, M. (1987). Psychosocial Resilience and Protective Mechanisms. American Journal of Orthopsychiatry, 57, 316-331. https://doi.org/10.1111/j.1939-0025.1987.tb03541.x

Stern, D. (1991). The Interpersonal World of the Infant. Buenos Aires: Paidos.

Weiss (1998). Patients Unconscious for Solving Their Problems. Psychoanalytic Dialo- 
gues, 8, 411-428. https://doi.org/10.1080/10481889809539259

Winnicott, D. (1975). The Maturational Processes and the Facilitating Environment: Studies in the Theory of Emotional Development. London: The Hogarth Press.

Winnicott, D. (1990). The Spontaneous Gesture: Selected Letters of D.W. Winnicott. Barcelona: Paidos Iberica.

Winnicott, D. (1991). Deprivation and Delinquency. Buenos Aires: Paidos.

Zukerfeld, R., \& Zonis Zukerfeld, R. (2005). Procesos terciarios. De la vulnerabilidad a la resiliencia. Editorial Lugar. 